\title{
Determination of Nicotine in Smoke Condensate by Ion Chromatography Coupled to Ultraviolet Detection*
}

\author{
by \\ Otmar Geiss and Dimitrios Kotzias
}

European Commission, Joint Research Centre, Institute for Health and Consumer Protection, 21020 Ispra (Va), Italy

\begin{abstract}
SUMMARY
A new method for the determination of the nicotine content of tobacco smoke condensate is described. The smoke condensate of the mainstream smoke was collected in a glass fibre filter trap and dissolved in isopropanol. The nicotine content of an aliquot of this solution was determined by ion chromatography (IC) coupled with ultraviolet (UV) detection against external calibration and the nicotine content of the whole smoke condensate was calculated. The nicotine content determined in each run by IC was compared with the results obtained by gas chromatography (GC) according to the International Standard (ISO) method 10315. The present method represents a potential alternative to the GC method. A sensitive and rapid method for the determination of nicotine in smoke condensate using IC with a standard ion chromatography column was developed. [Beitr. Tabakforsch. Int. 22 (2006) 307-311]
\end{abstract}

\section{ZUSAMMENFASSUNG}

Es wird eine neue Methode zur Bestimmung des Nikotingehalts im Tabakrauchkondensat beschrieben. Das Kondensat des Hauptstromrauchs wurde mit Hilfe eines Glasfaserfilters gesammelt und in Isopropanol gelöst. Die Nikotinkonzentration eines Aliquots dieser Lösung wurde mittels Ionenchromatographie (IC) und Ultraviolett-Detektion mit externer Kalibrierung bestimmt und der Nikotingehalt des gesamten Rauchkondensats berechnet. Der mittels IC bestimmte Nikotingehalt wurde mit den Ergebnissen der gaschromatographischen (GC) Methode gemäß ISO 10315 verglichen. Die vorgelegte Methode stellt eine potentielle Alternative zur gaschromatographischen Methode dar. Es wurde eine empfindliche und schnelle Methode zur Bestimmung von Nikotin im Rauchkondensat unter Verwendung der IC mit einer Standardsäule entwickelt. [Beitr. Tabakforsch. Int. 22 (2006) 307-311]

\section{RESUME}

Une nouvelle méthode pour la détermination de la teneur en nicotine dans le condensat de la fumée de tabac est présentée. Le condensat de fumée du courant principal est recueilli dans des filtres en fibre de verre et dissous dans de l'isopropanol. La teneur en nicotine d'un échantillon de cette solution est dosée par chromatographie ionique (IC) couplée à une détection dans l'ultraviolet (UV) avec étalonnage externe permettant de calculer la teneur en nicotine de l'ensemble du condensat de la fumée. La teneur en nicotine dosée à chaque passage par chromatographie ionique est comparée avec les résultats obtenus par chromatographie en phase gazeuse (GC) selon les conditions normalisées de l'Organisation Internationale de Normalisation de la méthode ISO 10315. Cette nouvelle méthode représente une alternative potentielle à la méthode GC. Une méthode sensible et rapide pour le dosage de la nicotine dans le condensat de fumée par IC sur une colonne de chromatographie ionique standard a été développée. [Beitr. Tabakforsch. Int. 22 (2006) 307-311]

\section{INTRODUCTION}

Nicotine is an alkaloid organic compound, occurring naturally in the nightshade family of plants, such as tobacco and tomatoes. It constitutes $0.3 \%$ to $18 \%$ of the tobacco

*Received: $20^{\text {th }}$ February 2006 - accepted: $7^{\text {th }}$ December 2006 


\begin{tabular}{|c|c|c|c|}
\hline Channel & & Concentration & $\%$ per channel \\
\hline A & Hydrochloric acid & $0.5 \mathrm{M}$ & 5 \\
\hline B & Deionized water Milli-Q & - & 23 \\
\hline C & Sodium chloride solution & $1 \mathrm{M}$ & 2 \\
\hline D & Acetonitrile & $90 \%$ acetonitrile / $10 \%$ water & 70 \\
\hline
\end{tabular}

plant in dry weight, with biosynthesis taking place in the roots, and accumulates in the leaves (2). During the combustion reaction that occurs when cigarettes are lit, a fraction of nicotine present in the tobacco is transferred to the inhaled smoke. In the low concentrations found in cigarette smoke, the substance is a stimulant and it is one of the main factors leading to the pleasure and habit-forming qualities of tobacco consumption (3).

The European Parliament adopted in 2001 the European Directive 2001/37/EC (4) that regulates the maximum allowed nicotine yields (1 $\mathrm{mg}$ nicotine/cig) of cigarette smoke, determined by a standardised smoking machine test following the International Standard (ISO) 3308 method (5). It is therefore necessary to have a method for a reliable determination of the maximum amount of nicotine in cigarette smoke. The ISO 10315 method (1) has been selected as reference method. This ISO method uses gas chromatography (GC) combined with flame ionization detection (FID) for the determination of nicotine in mainstream smoke condensate. In the absence of a gas chromatographic system it is useful to have a valid alternative to the GC method. In this paper a potential alternative method was developed using an ion chromatographic (IC) method coupled with UV detection. Short analysis time, good peak-resolution and high sensitivity make this method suitable for the determination of nicotine in smoke condensate. Smoking and the collection of mainstream smoke are normally carried out in accordance with ISO 4387, ISO 3308 and ISO 3402 (5-7).

\section{MATERIALS AND METHODS}

\section{Instruments}

The IC method used in this work was carried out with a Dionex DX-500 system (Dionex Corporation, 1228 Titan Way, Sunnyvale, CA 94085, USA), composed of a GP-40 gradient pump, an AS50 auto sampler and an AD20 absorbance detector all under software control (Peaknet 5.2). The chromatographic separations were obtained with a standard IonPac CS12 $(4 \times 250 \mathrm{~mm})$ Dionex column. A single channel Borgwaldt RM-1 Plus smoking machine (Borgwaldt $\mathrm{KC} \mathrm{GmbH}$, Hamburg, Germany) was used. The GC separation was performed with an Agilent 6890 Network gas chromatographic system in combination with a flame ionisation detector (Agilent Technologies, Inc., Santa Clara, CA 94306, USA). The column employed for the gas chromatographic analysis was a DB-WAX $(30 \mathrm{~m}, 0.25 \mathrm{~mm}$ ID, $0.5 \mu \mathrm{m}$ film, Code 122-7033) (C.P.S. Analitica S.r.l., Milan, Italy).

\section{Consumables}

All chemicals used were analytical-reagent grade or better. Deionized water was obtained from a Millipore Milli-Q system (Millipore Corporate Headquarters, 290 Concord Rd. Billerica, MA 01821, USA). The chemicals used for the mobile phase were methanesulfonic acid (Fluka 64280, Sigma-Aldrich Srl, Milan, Italy) and acetonitrile (Aldrich 27071-7). The extraction of nicotine from the filter pad was done using isopropanol (Aldrich 27049-0). The nicotine used for the preparation of the standards had a purity of 98-100\% (Aldrich N-3876). The internal standard solution for the gas chromatographic analysis was prepared with $n$ heptadecane (purity 99.5\%, Riedel-de Haen, Sigma-Aldrich Srl, Milan, Italy). The disc filters used for the filtration step of the extract were made of polytetrafluoroethylene (PTFE) with polypropylene housing with a pore dimension of 0.45 $\mu \mathrm{m}$ (Whatman, $25 \mathrm{~mm}$ disposable filter devices, Cat.No. 68 74-2504, Whatman International Ltd, Springfield Mill, James Whatman Way, Maidstone Kent, ME14 2LE, UK). $44 \mathrm{~mm}$-glass fiber filter pads were used (Borgwaldt, Code 8020285 1) for the deposition of mainstream smoke condensate.

\section{Procedures}

Ion chromatographic parameters: The chromatographic conditions applied were a flow-rate of $1 \mathrm{~mL} / \mathrm{min}$, injection volume of $50 \mu \mathrm{L}$ and detector wavelength of $254 \mathrm{~nm}$. The composition of the mobile phase (isocratic solvent composition) is given in Table 1 .

Smoking machine: Standard conditions were as follows (5): Puff duration, $2.0 \mathrm{sec}$; puff volume, $35.0 \mathrm{~mL}$; puff frequency, one puff every $60 \mathrm{sec}$, puff profile, bell-shaped.

Gas chromatographic parameters: Injector/detector temperature, $240{ }^{\circ} \mathrm{C}$; constant flow mode, $1.2 \mathrm{~mL} / \mathrm{min} \mathrm{He}$; split ratio, 1:50; injection volume, $2 \mu \mathrm{L}$.

Oven program initial temperature, $160{ }^{\circ} \mathrm{C}$ for $4.5 \mathrm{~min}$; Ramp, $20{ }^{\circ} \mathrm{C} / \mathrm{min}$ up to $230{ }^{\circ} \mathrm{C}$; final temperature, $230{ }^{\circ} \mathrm{C}$ for $6 \mathrm{~min}$; total runtime, $14 \mathrm{~min}$.

\section{Sample preparation}

Three brands with nicotine contents ranging from 0.1 to 1.3 $\mathrm{mg}$ nicotine/mainstream smoke condensate of one cigarette were analysed in this study. Fifteen replicate measurements were made for each brand by smoking five cigarettes per replicate according to the ISO 3308 (5) smoking regime. The condensate was collected on a $44 \mathrm{~mm}$ glass-fibre filter pad. The filter pad was then transferred to an Erlenmeyer 

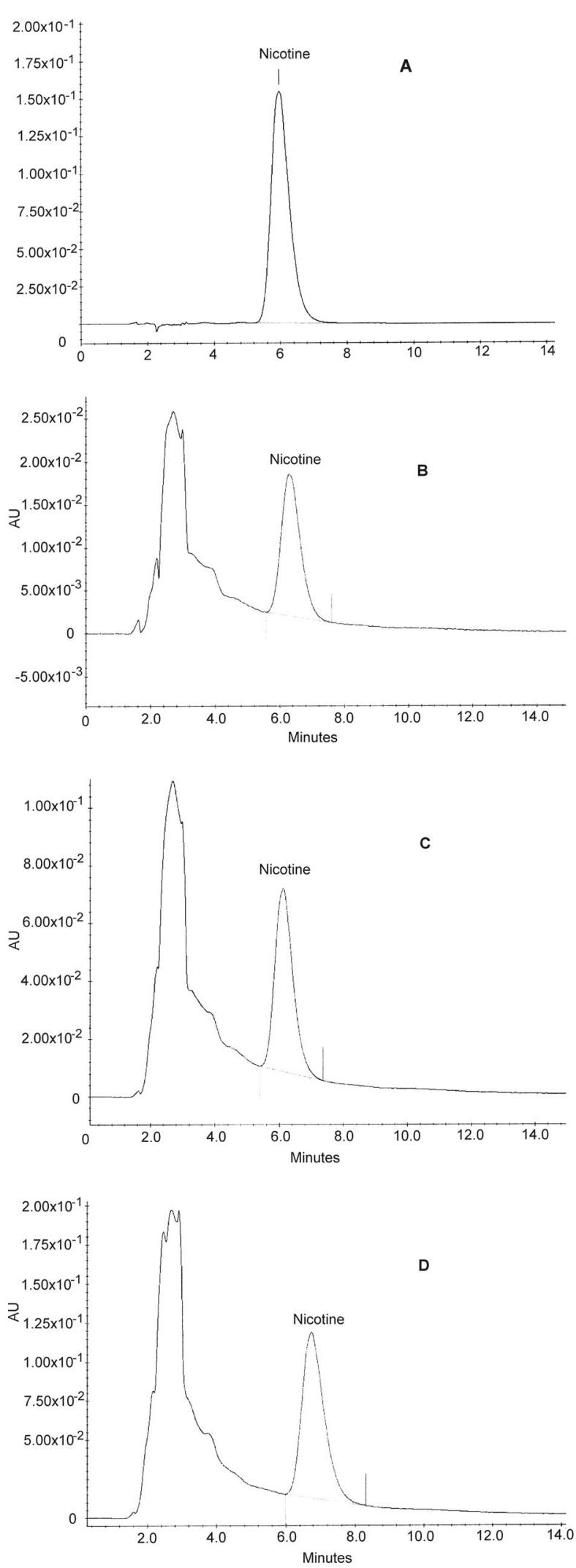

Figure 1. Ion chromatogram of a medium level nicotine standard solution (A), filter-pad extract (Brand A) (B), filterpad extract (Brand B) (C), and ion chromatogram of filter-pad extract (CORESTA Monitor Cigarette CM4) (D) flask and was subsequently extracted with $50 \mathrm{~mL}$ isopropanol. Extraction time was $30 \mathrm{~min}$ and was followed by filtering through a $0.45 \mu \mathrm{m}$ disc filter.

Sample preparation for gas chromatographic analysis: An aliquot of exactly $25 \mathrm{~mL}$ of the filtered extract was taken and $150 \mu \mathrm{L}$ of the internal standard were added (internal standard: $n$-heptadecane $=1.5 \mathrm{mg} / 150 \mu \mathrm{L}$ ). This solution was analysed by GC and quantified against the internal standard. The calibration curve was prepared in isopropanol and ranged from $0.48 \mathrm{mg}$ nicotine $/ 50 \mathrm{~mL}$ isopropanol to $6.2 \mathrm{mg}$ nicotine $/ 50 \mathrm{~mL}$ isopropanol with the concentration of the internal standard ( $n$-heptadecane) being $3.9 \mathrm{mg} / 50 \mathrm{~mL}$ isopropanol.

Sample preparation for ion chromatographic analysis: An aliquot of the filtered extract was analysed directly by IC and quantified against an external calibration curve. The calibration curve was prepared in isopropanol and ranged from $0.48 \mathrm{mg}$ nicotine $/ 50 \mathrm{~mL}$ isopropanol to $6.3 \mathrm{mg}$ nicotine $/ 50 \mathrm{~mL}$ isopropanol.

\section{RESULTS AND DISCUSSION}

\section{Chromatography}

The developed IC method returned a well separated nicotine peak for all three brands (Figures 1a-1d) at a retention time of approximately $6.0 \mathrm{~min}$. The peak area response was linear over the concentration range of the prepared standard solutions. The concentrations of the standards (the standards were prepared in isopropanol) ranged from $0.48-6.25 \mathrm{mg} / 50 \mathrm{~mL}$. The $R^{2}$-value was 0.9992 .

Based on standard chromatograms obtained using a $50 \mu \mathrm{L}$ injection loop, the absolute limit of detection determined as a peak height three times the baseline, was $2 \mu \mathrm{g} / 50 \mathrm{~mL}$ isopropanol (filter pad extract). With the smoking machine smoking five cigarettes under a prescribed smoking regime, the relative detection limit is approximately $0.4 \mu \mathrm{g}$ nicotine/mainstream smoke condensate of one cigarette (corresponding to a limit of quantification of $1.2 \mu \mathrm{g}$ nicotine/mainstream smoke condensate of one cigarette).

\section{Test measurements}

Three different cigarette brands with nicotine contents ranging from $0.1 \mathrm{mg}$ to approximately $1.3 \mathrm{mg}$ nicotine/ mainstream smoke condensate of one cigarette were investigated in this study (Table 2). Brands A and B are commercially available on the market.

Table 2. Nicotine contents of mainstream smoke condensate (MSC) of investigated cigarettes collected under prescribed smoking regime as stated on cigarette box

\begin{tabular}{lc}
\hline Cigarettes & $\begin{array}{c}\text { Nicotine content / MSC } \\
\text { of one cigarette [mg] }\end{array}$ \\
\hline Brand A (American Blend) & 0.1 \\
Brand B (American Blend) & 0.4 \\
CORESTA Monitor Cigarette 4 (CM4) & $1.3^{\mathrm{a}}$ \\
\hline
\end{tabular}

a Statistical results. Statistical report may be obtained from CORESTA (11, rue du Quatre Septembre, F-75002 Paris) 


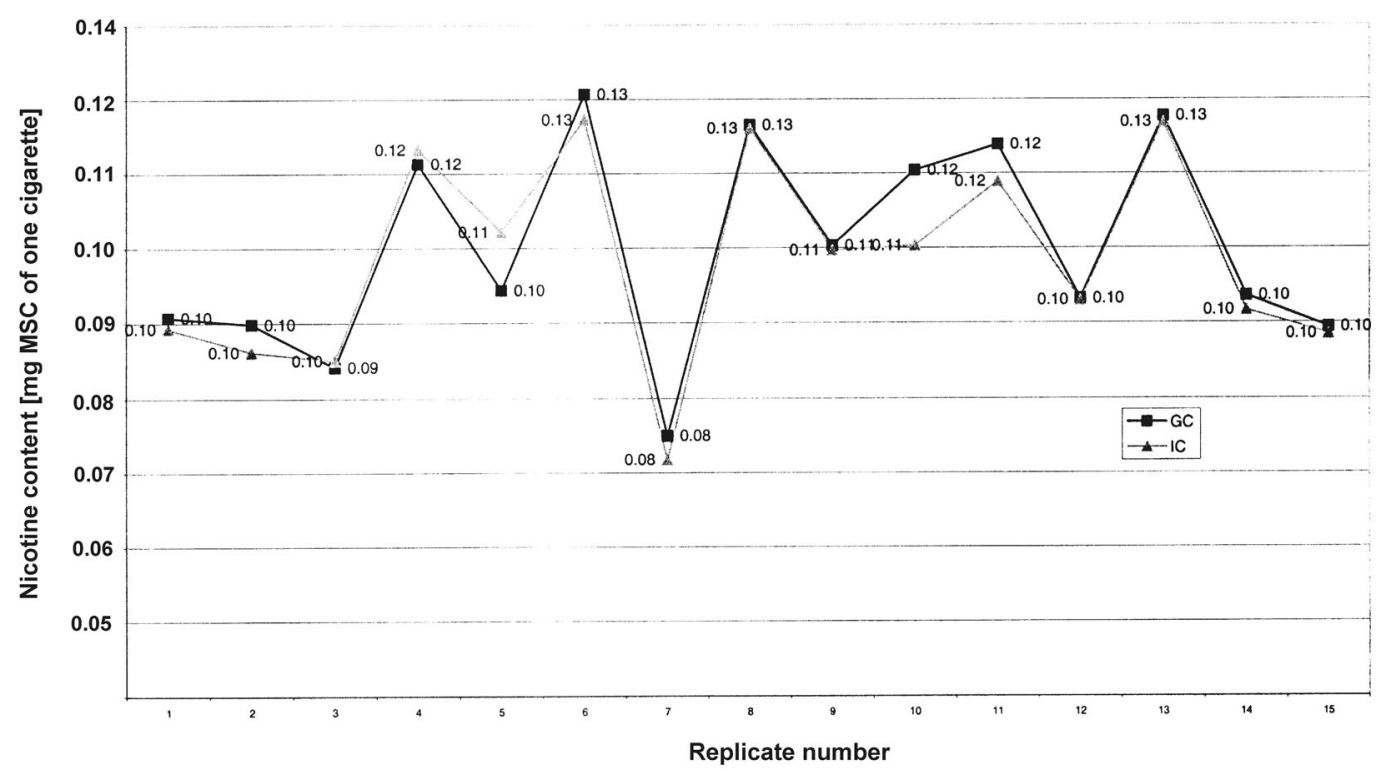

Figure 2a. Brand A: Comparison of results obtained by IC and GC

Brand B

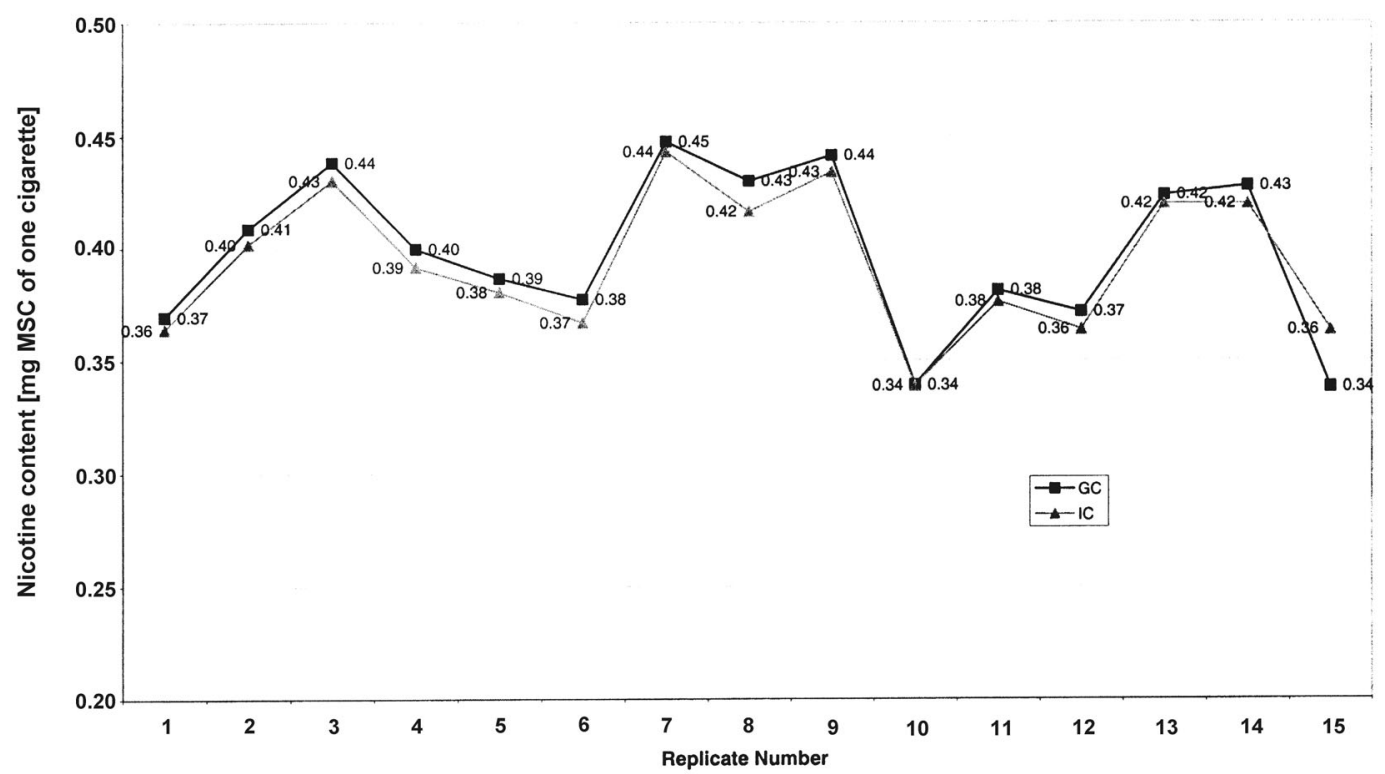

Figure $2 \mathrm{~b}$. Brand B: Comparison of results obtained by IC and GC

Fifteen replicate measurements were made for each brand by smoking five cigarettes per replicate according to the ISO 3308 (5) smoking regime. The extract obtained by adding isopropanol to the mainstream smoke condensate on the filter pad was then used for both IC as well as GC analysis. The GC analysis was performed according to the ISO 10315 (1) method.

Figures $2 \mathrm{a}-2 \mathrm{c}$ summarise the results obtained. It can be seen that the results obtained by the IC method are matching well in all cases with those obtained by the standardised GC method. For brand A, the largest observed difference was of $0.01 \mathrm{mg}$ nicotine (replicates nos. 3, 5 and 10), for brand B it was $0.02 \mathrm{mg}$ nicotine (replicate no. 15) and finally, for the CM4 it was $0.1 \mathrm{mg}$ nicotine (replicates no. 4 and no. 11).

\section{CONCLUSIONS}

A sensitive, rapid (less than 15 min per analysis) method for the determination of nicotine in smoke condensate using IC is described. The results obtained by analysing the same filter-pad extract with both the gas chromatographic ISO method and the ion chromatographic method as described, allows a direct comparison and reveals good matching results.

The method was found to be linear in response over the investigated concentration range $(0.48-6.2 \mathrm{mg} / 50 \mathrm{~mL})$ and has a detection limit of $0.4 \mu \mathrm{g} / \mathrm{cig}$ (smoking five cigarettes) for a $50 \mu \mathrm{L}$ injection loop.

This method appears to be a potential alternative to the gas chromatographic ISO method, future efforts are however 


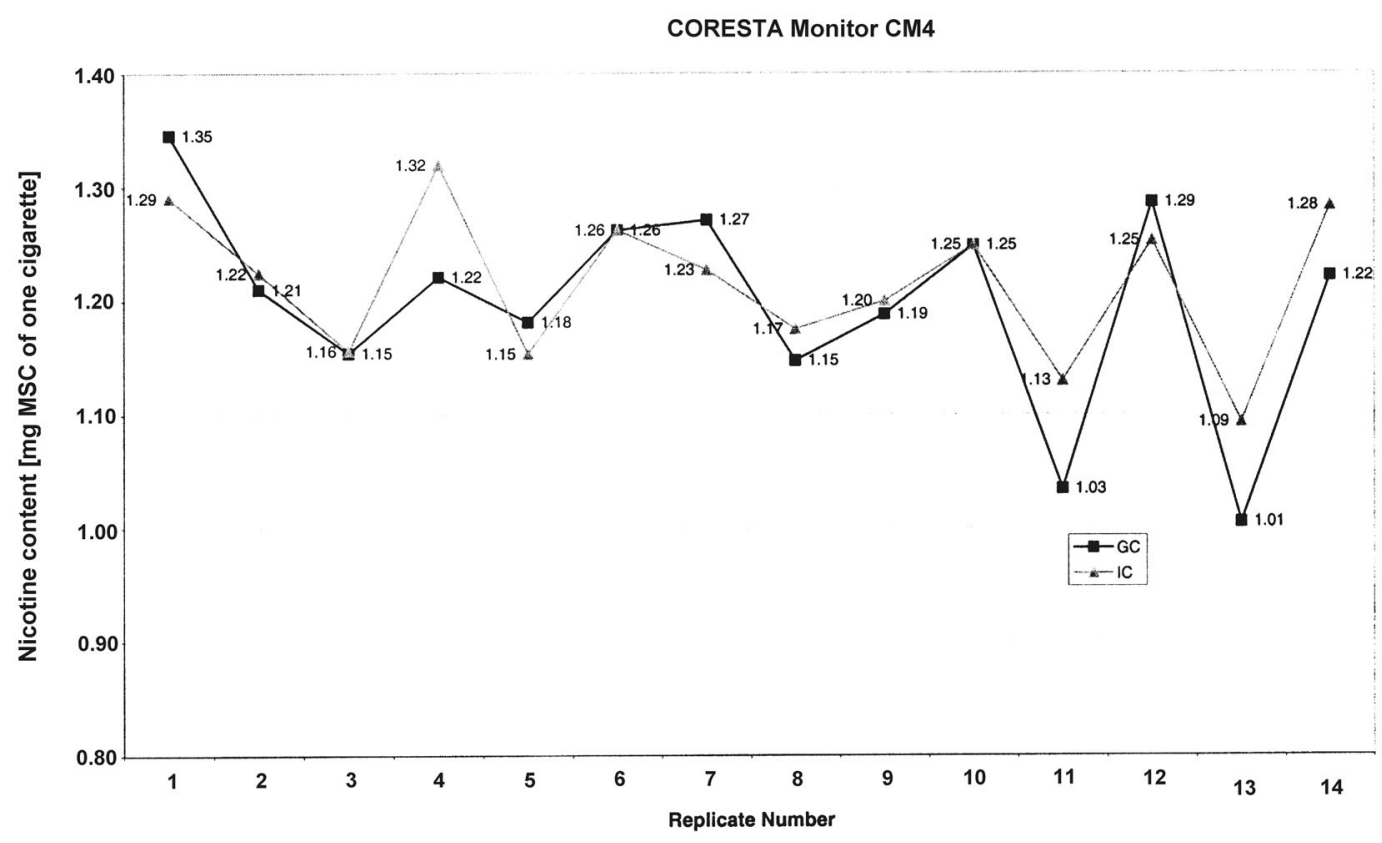

Figure 2c. CORESTA Monitor CM4: Comparison of results obtained by ion chromatography and gas chromatography

necessary to obtain a more detailed evaluation of the method validity.

The results obtained in this study indicate that further investigation is valuable, including the assessment of repeatability/reproducibility, storage stability and matrix effects (smoking many more types of cigarette samples with varying types and blends of different tobaccos and additives).

\section{REFERENCES}

1. ISO 10315:2000: Cigarettes - Determination of nicotine in smoke condensates - Gas Chromatographic Method; International Organization for Standardization, Geneva, Switzerland, Second edition, 2000.

2. Franke, W.: Nutzpflanzenkunde: Nutzbare Gewächse der gemäßigten Breiten, Subtropen und Tropen [Agricultural crops in temperate latitudes, the subtropics and the tropics]; 6. Auflage, Stuttgart, New York, Thieme, 1997.

3. Gad, S.C.: Tobacco smoke; in: Encyclopaedia of Toxicology, Vol. 3, edited by P. Wexler, Academic Press, San Diego, 1998, pp. 247-248.

4. European Parliament and the Council: Directive 2001/37/EC: On the approximation of the laws, regulations and administrative provisions of the Member States concerning the manufacture, presentation and sale of tobacco products; adopted by the European Parliament and the Council on 5 June 2001.
5. ISO 3308: Routine analytical cigarette-smoking machine - Definitions and standard conditions; International Organization for Standardization, Geneva, Switzerland, fourth edition, 2000.

6. ISO 4387: Cigarettes - Determination of total and nicotine-free dry particulate matter using a routine analytical smoking machine; International Organization for Standardization, Geneva, Switzerland, third edition, 2000.

7. ISO 3402: Tobacco and tobacco products - Atmosphere for conditioning and testing; International Organization for Standardization, Geneva, Switzerland, fourth edition, 1999.

Address for correspondence:

Otmar Geiss

European Commission

Joint Research Centre

Institute for Health and Consumer Protection

21020 Ispra ( Va)

Italy

E-mail: otmar.geiss@jrc.it 